\title{
EVALUATION OF INTERNAL STRESSES AND ITS IMPACT ON THE CONCRETE/CEMENT MORTAR MASS PREPARED WITH RECYCLED DEMOLISHED CONCRETE AGGREGATES
}

\author{
D. Durga Prasad* \\ Research Scholar, Department of Civil Engineering, UCE, OU, Hyderabad, India. \\ Kishore Ravande \\ Principal \& Dean MIT School of Engineering, MIT-ADT University of Pune, \\ Ex Dean Faculty, UCE, OU, Hyderabad, India. \\ *Corresponding Author
}

\begin{abstract}
In Concrete /Cement Mortar Mass a significant study was made on the applied stress and on this applied stress the design criteria of the structures have been finalised and a limited study on the internal built in stress was made and minimal studies on its effects. Since, in any material the internal stress, i.e. residual stress plays a vital role and it defines the internal anatomy and its behaviour. The present research work concentrates on the studies done in assessing the residual stress i.e. macro and micro stress and its impact on the concrete /cement mortar mass prepared with untreated and treated recycle demolished coarse and fine aggregates and compared with that of concrete/mortar mass prepared with that of conventional aggregates. The XRD is used to evaluate the macro and micro stress and on the obtained results it was found that type of stress developed plays a vital role in defining the internal integrity of the structure and the amount of the stress play a significant role in the performance of the concrete/mortar mass and the residual stress developed decides the durability of the structure in terms of its fatigue life, resistance to corrosion and the dimensional stability overall.
\end{abstract}

Keywords: Strength, Recycled aggregates, Treated aggregates, Residual Stresses, Macro and Micro Stresses, XRD, Concrete, Cement Mortar

Cite this Article: D. Durga Prasad and Kishore Ravande, Evaluation of Internal Stresses and its Impact on the Concrete/Cement Mortar Mass Prepared with Recycled Demolished Concrete Aggregates, International Journal of Civil Engineering and Technology, 12(1), 2021, pp. 25-40.

https://iaeme.com/Home/issue/IJCIET?Volume $=12 \&$ Issue $=1$ 


\section{INTRODUCTION}

\subsection{General}

Any raw materials when it is made into final product the process of conversion of the state involves either surface enhancement, heating treatment etc the process of change of state adds residual stress to the final product, in shot the residual stress is the internal stress distribution locked inside an object. In concrete/Mortar mass the main cause of residual stress is the solidification of the materials and the phases changes i.e. phase transformation resulting in a volume changes. The developed residual stress vary from grains to grains in its internal atomic structure and based on this the stresses has been categorized into macro, micro and sub-micro stress. The macro stress is the average stress over a group of grains in a material and Micro stress is the residual stress between the grains variations may result between the different phases in the material, the sub -micro stress is the residual stress with one grain, variation may result in dislocation and crystalline defects. The nature of this stress plays a vital role in deciding the dimensional stability of the material. The residual stresses may be sufficiently large to cause local yielding and plastic deformation, both on a microscopic and macroscopic level, and can severely affect component performance. For this reason it is vital that some important knowledge of the internal stress state can be deduced either from measurements or modelling predictions. Both the magnitude and distribution of the residual stress can be critical to performance and should be considered in the design of a component. In any free standing body stress equilibrium must be maintained, which means that the presence of a tensile residual stress in the component will be balanced by a compressive stress elsewhere in the body. Tensile residual stresses in the surface of a component are generally undesirable since they can contribute to, and are often the major cause of, fatigue failure, quench cracking and stress, corrosion cracking. Compressive residual stresses in the surface layers are usually beneficial since they increase both fatigue strength and resistance to stress-corrosion cracking, and increase the bending strength of brittle ceramics and glass. As defined by F A Kandil [1], the origins of residual stresses in a component may be classified as :(a).Mechanical (b).Thermal (c).Chemical ... Mechanically generated residual stresses are often a result of manufacturing processes that produce non-uniform plastic deformation. Microscopic thermally generated residual stresses can also develop in a material during manufacture and processing as a consequence of the CTE $\left(\alpha_{0}\right)$ mismatch between different phases or constituents. The chemically generated stresses can develop due to volume changes associated with chemical reactions, precipitation, or phase transformation. Chemical surface treatments and coatings can lead to the generation of substantial residual stress gradients in the surface layers of the component. In concrete and cement mortar the residual stress development is mainly due to chemical reaction and the internal stress developed and its impact are evaluated and its in-detail analysis has been dealt accordingly.

\subsection{Objectives of the work}

The following are the main objectives to achieve the major goal.

- To evaluate the Macro and Micro Stress of the concrete /cement mortar mass prepared with different types of aggregates.

- To study the significant impact of residual stress on the concrete/mortar mass and its effects on the total stress.

\subsection{Formation and Significance of Internal Stress}

Internal stress is that which remains in a body that is stationary and at equilibrium with its surroundings. It can be very detrimental to the performance of a material or the life of a structure. Alternatively, beneficial internal/residual stresses can be introduced deliberately. 
Residual stresses are more difficult to predict than the in-service stresses on which they superimpose. For this reason, it is important to have reliable methods for the measurement of these stresses and to understand the level of information they can provide. To determine the stress, the strain in the crystal lattice must be measured for at least two precisely known orientations relative to the sample surface. Therefore, $\mathrm{x}$-ray diffraction residual stress measurement is applicable to materials that are crystalline, relatively fine grained, and produces diffraction for any orientation of the sample surface. Samples may be metallic or ceramic, provided a diffraction peak of suitable intensity and free of interference from neighboring peaks can be produced in the high back-reflection region with the radiations available. X-ray diffraction residual stress measurement is unique in that macroscopic and microscopic residual stresses can be determined non-destructively. Residual stresses can be characterized by the scale at which they exist within a material. As defined in introduction Stresses that occur over long distances within a material are referred to as macro-stresses. Stresses that exist only locally (either between grains or inside a grain) are called micro-stresses. The total residual stress at a given location inside a material is the sum of two types of stresses and the same is elaborated in detail as stated below,

Importance of Macroscopic stresses, or macro stresses:- which extend over distances that are large relative to the grain size of the material, are of general interest in design and failure analysis. Macro stresses are tensor quantities, with magnitudes varying in direction at a single point in a body. The macro stress for a given location and direction is determined by calculating the strain in that direction at a single point. When macro stresses are determined in at least three known directions, and a condition of plane stress is assumed, the three stresses can be combined using Mohr's circle for stress to determine the maximum and minimum residual stresses, the maximum shear stress, and their orientation relative to a reference direction. Macro stresses strain many crystals uniformly in the surface. This uniform distortion of the crystal lattice shifts the angular position of the diffraction peak selected for residual stress measurement.

Importance of Microscopic stresses, or micro stresses:- are scalar properties of the sample, such as percent of cold work or hardness that are without direction and result from imperfections in the crystal lattice. Micro stresses are associated with strains within the crystal lattice that traverse distances on the order of or less than the dimensions of the crystals. Micro stresses vary from point to point within the crystal lattice, altering the lattice spacing and broadening the diffraction peak. Macro stresses and micro stresses can be determined separately from the diffraction peak position and breadth.

Importance of Net Induced Stresses:- The net induced stress experienced by the material at a given location within a component is equal to the Macro stress plus Micro stress plus the applied stress.

NET INDUCED STRESS $=$

MACRO STRESS + MICRO STRESS+ APPLIED STRESS----

INTERNAL STRESS/RESIDUAL STRESS

If a material with a residual stress of a $-10 \mathrm{MPa}$ is subjected to an applied load of $+34 \mathrm{MPa}$. The net stress experienced by the material is the summation of the two stresses, or +24 MPa. Therefore, knowledge of the residual stress state is important to determine the actual loads experienced by a component. In general, compressive residual stress in the surface of a component is beneficial. It tends to increase fatigue strength and fatigue life, slow crack propagation, and increase resistance to environmentally assisted cracking such as stress corrosion cracking and hydrogen induced cracking. Tensile residual stress as shown in below figure in the surface of the component is generally undesirable as it decreases fatigue strength 
and fatigue life, increases crack propagation and lowers resistance to environmentally assist cracking.

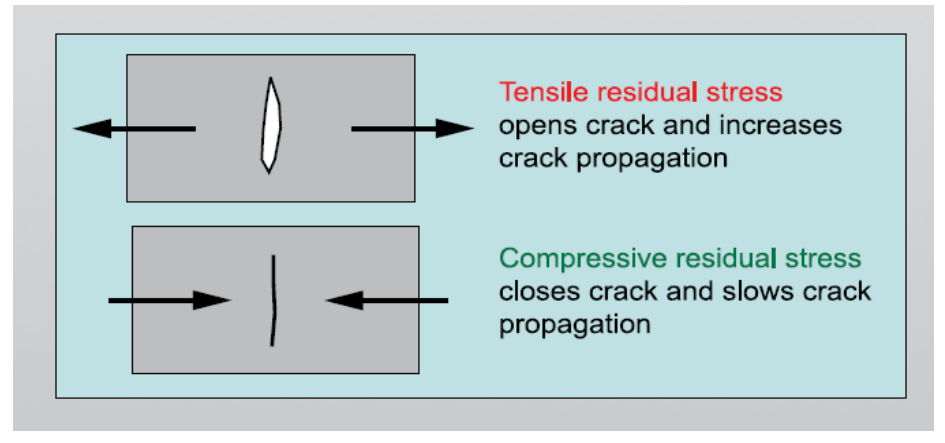

Figure 1 Types of Residual Stress at Macro and Micro Level

Source: - Proto Manufacturing-x ray Diffraction Residual Stress Measurement

\section{EXPERIMENTAL WORK}

With an intention of the cent percentage utilization of recycled demolished coarse and fine aggregates in concrete/mortar preparations. The tests were done in the laboratory, on recycled demolished concrete coarse and fine aggregate with various surface modification and surface treatments viz., Densification, Hydrophobization, Polymerization and a combination of Densification and Polymerization and on treated aggregates physical properties have been evaluated and on the improved properties the best combination has been selected and on these combinations, the concrete /mortar specimens has been cast and tested for its compressive. Based on the test results it was found that a densification process of surface treatment method is effective in improving the properties of the aggregates and the concrete/mortar mass prepared i.e., a final combination of $2.5 \%$ of lithium silicate treatment on a recycled demolished concrete coarse aggregate and 1\% colloidal silica dioxide treatment on demolished concrete fine aggregate found to be the best treatment for its usage in concrete and $1 \%$ colloidal silica treatment on recycled fine aggregate in its usage in preparation of cement mortar. The test values of compressive strength on cement mortar are depicted in figure 1 . Table 01 depicts the Mix design adopted on concrete samples.

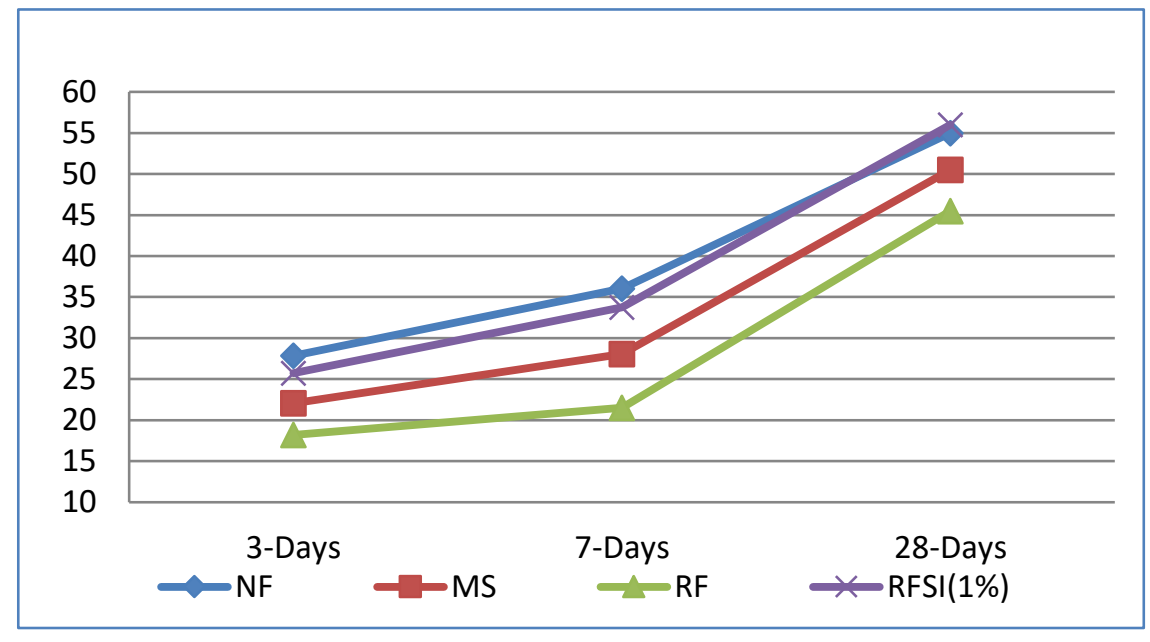

Figure 2 Compressive Strength ( IN Mpa) on Cement Mortar Cubes Prepared with Various Types of Fine Aggregates 
Table 1 M30 Grade Concrete Mix Design Using Different Types of Coarse and Fine Aggregates

\begin{tabular}{|l|c|c|c|c|}
\hline $\begin{array}{l}\text { Final Proportion } \\
\text { of materials at the } \\
\text { site }\end{array}$ & $\begin{array}{c}\text { NCA+N } \\
\text { FA }\end{array}$ & $\begin{array}{c}\text { NCA+M- } \\
\text { Sand }\end{array}$ & $\begin{array}{c}\text { RCA+R } \\
\text { FA }\end{array}$ & $\begin{array}{c}\text { RCA(2.5 } \\
\text { \%LI)+ } \\
\text { RFA(1\% } \\
\text { SI) }\end{array}$ \\
\hline Water(ltr) & 161.278 & 176.65 & 210.14 & 223.98 \\
\hline Cement(Kg) & 350.22 & 350.22 & 350.22 & 437.77 \\
\hline $\begin{array}{l}\text { Chemical } \\
\text { Admixture(ltr) }\end{array}$ & 2.98 & 2.98 & 2.98 & 0 \\
\hline $\begin{array}{l}\text { Fine } \\
\text { Aggregate(kg) }\end{array}$ & 698.865 & 688.57 & 536.7 & 613.94 \\
\hline $\begin{array}{l}\text { Coarse } \\
\text { Aggregate(kg) }\end{array}$ & 1190.72 & 1190.72 & 1152.94 & 1179.57 \\
\hline
\end{tabular}

\subsection{Mechanical Properties Evaluation on Hardened Concrete}

On a final combination of $2.5 \%$ of lithium silicate treatment on recycled demolished concrete coarse aggregate and 1\% colloidal silica dioxide treatment on demolished concrete fine aggregate to test it mechanical properties a set of cubes, cylinders and prisms were casted and tested for compressive strength, split tensile strength, flexural strength, shear strength impact strength, and for stress strain analysis. And the same were compared with that of cubes casted with Natural Coarse and fine aggregates and also with recycled coarse and fine aggregate. The results of the compressive strength are graphically presented at Figures.3, All the mechanical properties on hardened concrete prepared with treated recycled demolished concrete coarse and fine aggregates have shown improved performance as compared with that of concrete made of untreated recycled aggregates,

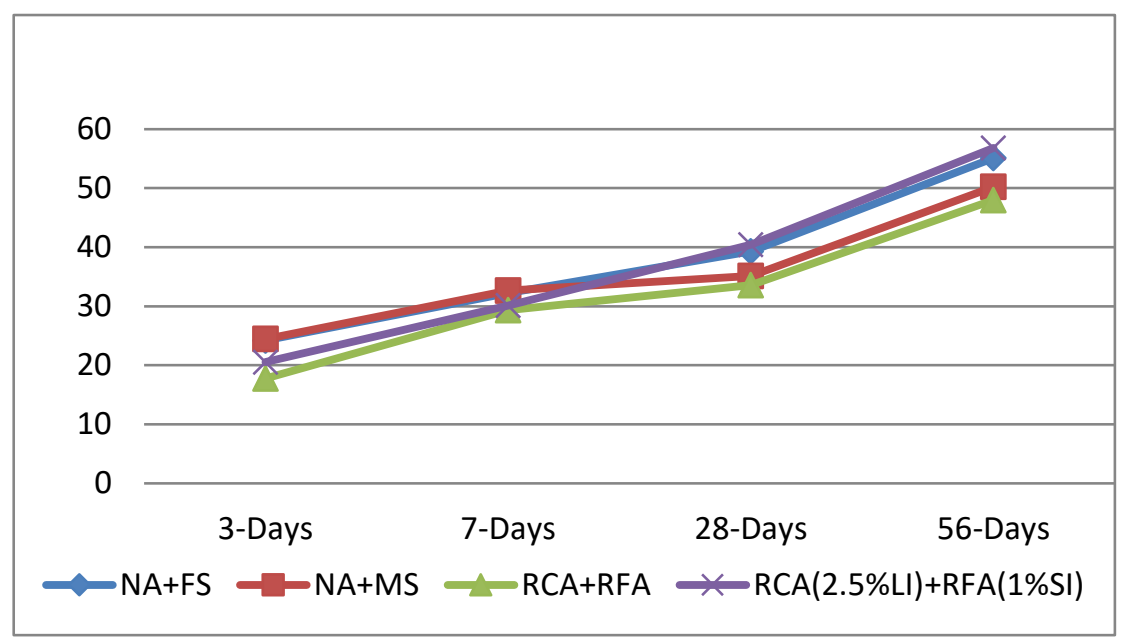

Figure 3 Compressive Strength ( IN Mpa) of Concrete Cubes Prepared with Various Types of Aggregates Based on Best Combination

\subsection{XRD Analysis}

Using laboratory-based equipment's, the XRD technique measures surface residual stresses to depths of up to $30 \mu \mathrm{m}$ by measuring the material's inter-atomic spacing. Laboratory X-rays have wavelengths of the order of a few angstroms $(\AA)$, which is the same order of magnitude as the typical inter-atomic/inter-planar distances in polycrystalline solids. X-rays scattered from a polycrystalline solid can constructively interfere producing a diffracted beam. The angles at which the maximum diffracted intensities occur are measured. From these angles it is possible to obtain the inter-planar spacing, $d$, of the diffraction planes using Bragg's law. If residual stresses exist within the sample, then the $\mathrm{d}$ spacing will be different from that of an unstressed 
sample (i.e. $\mathrm{d}_{0}$ ). The difference is proportional to the magnitude of residual stress present. In principle therefore, we use the grains as internal strain gauges for residual (or applied) stresses. The diffraction pattern for every phase is as unique as our fingerprint. Phases with the same chemical composition can have drastically different diffraction patterns. - Use the position and relative intensity of a series of peaks to match experimental data to the reference patterns in the database. The phase identification has been done by using the XRD data and by using Match software and details of which are depicted at Figure $4 \& 5$, for concrete/mortar mass prepared with treated aggregates. The Match software helps is assessing the

Crystalline Size, Interplanar Spacing and dislocation density. Crystallite size is normally defined as a size of a single crystal within a polycrystalline solid. Crystallites smaller than $\sim 120 \mathrm{~nm}$ create broadening of diffraction peaks - this peak broadening can be used to quantify the average crystallite size of nanoparticles using the Scherrer equation - must know the contribution of peak width from the instrument by using a calibration curve. Similarly the XRD diffraction data helps in identification of interplannar spacing between the crystalline planes, and also the "Dislocation density (DD). DD is a measure of the number of dislocations in a unit volume of a crystalline material". The total length of dislocation line in a unit volume is measured and divided by the volume to give $r_{D}=\left(L / 1^{3}\right) \mathrm{m}^{-2}$, Using the Origin Pro software and by feeding the diffraction data in the software, we can evaluate the dislocation density by the formula $\delta=\left(1 / \mathrm{D}^{2}\right)$.The data so gathered helps in evaluation of macro and Micro stress which are discussed in details at Figures $7 \& 12$.

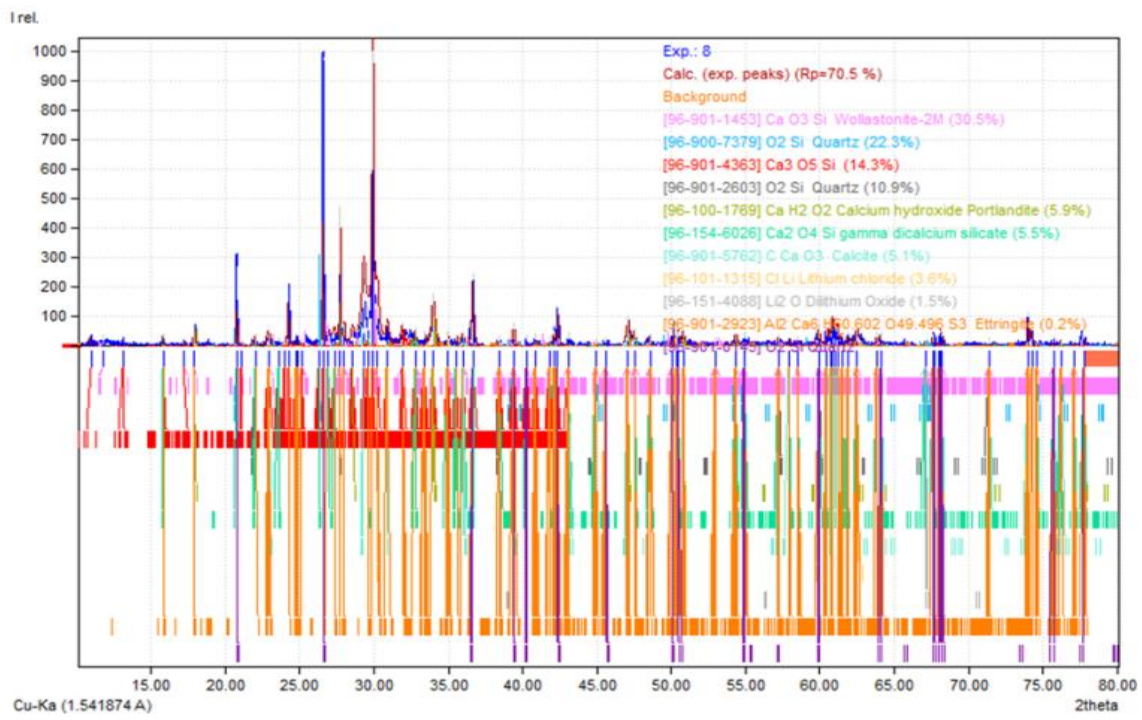

Figure 4 Diffraction Pattern Graph of Concrete SPECIMEN Prepared with Treated Recycled Demolished ConCrete Coarse and Fine Aggregates 


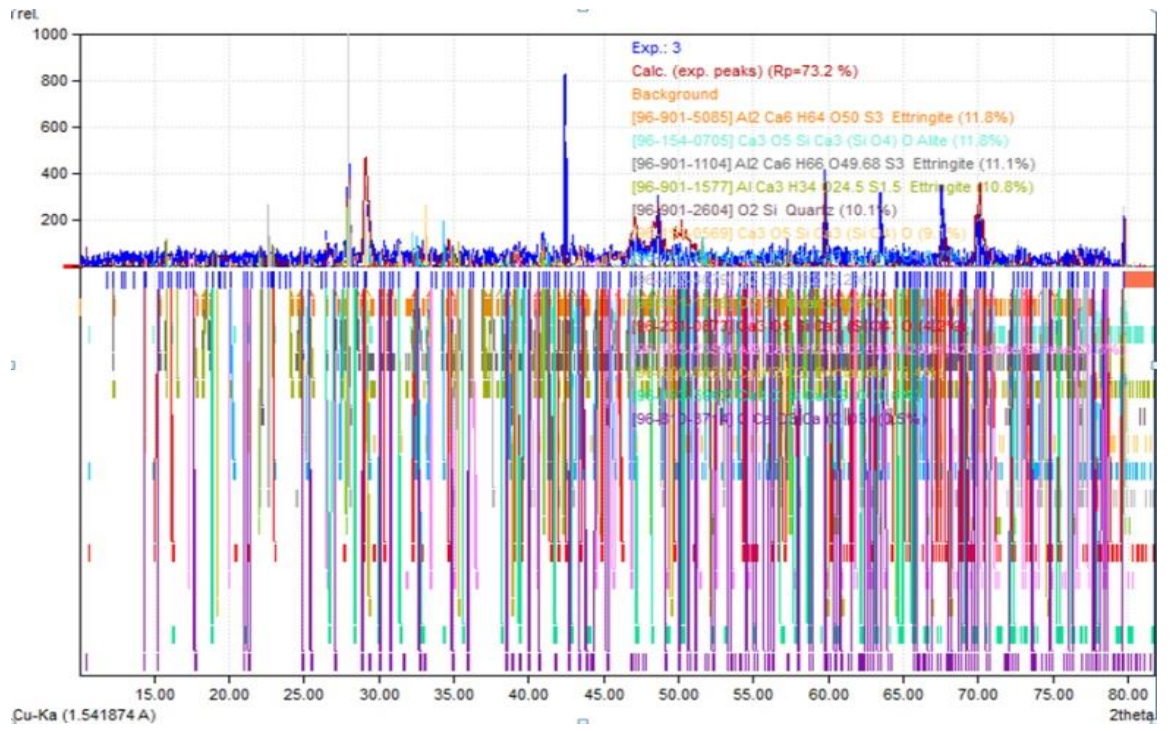

Figure 5 Diffraction Pattern Graph of Cement Mortar Prepared with Treated Recycled Demolished Concrete Fine aggregate

\section{EVALUATION OF RESIDUAL STRESS}

\subsection{Macro Stress Calculation}

$\mathrm{X}$-ray diffraction stress measurement is confined to the surface of the sample. Electro polishing is used to expose new surfaces for subsurface measurement. In the exposed surface layer, a condition of plane stress is assumed to exist. That is, a stress distribution described by principal stresses $\sigma 1$ and $\sigma 2$ exists in the plane of the surface, and no stress is assumed perpendicular to the surface, $\sigma 3=0$. Based on the above the normal stress at a point is derived by equation (B) and the differentiate part is obtained by slope of the graph of plot made between $\mathrm{d}$ vs $\operatorname{Sin}^{2} \psi$, were $\psi$ is the inclination plane of the sample. The below table in Figures 07, tabulates the calculation of macrostrain and stress from X-ray diffraction data.

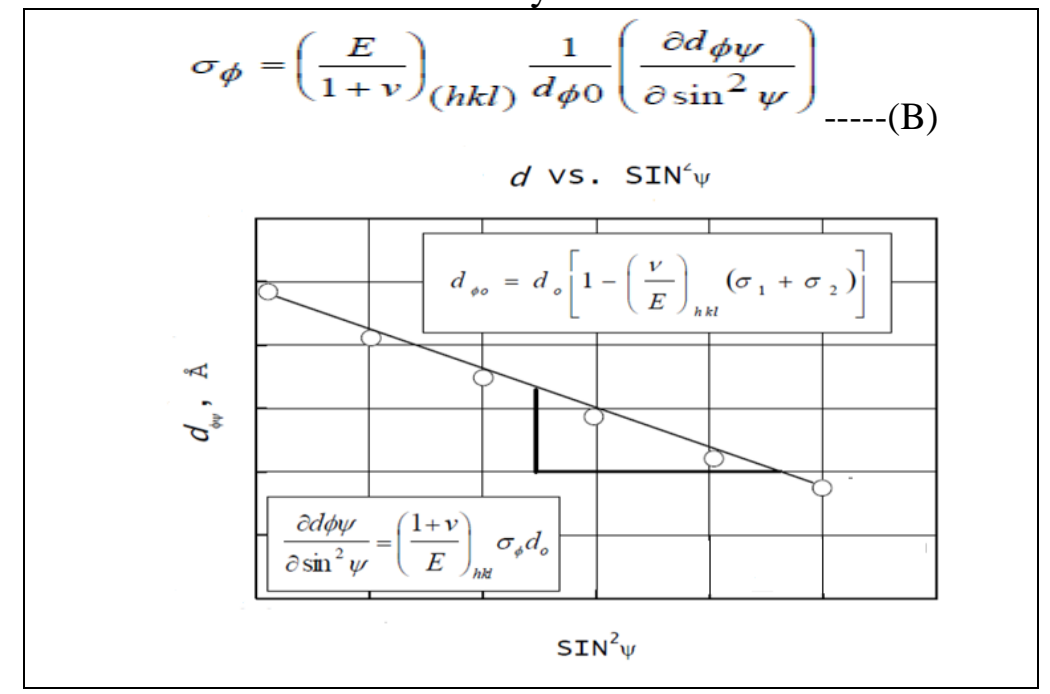

Figure 6 Pattern of $d$ vs $\operatorname{Sin}^{2} \psi$ 
Evaluation of Internal Stresses and its Impact on the Concrete/Cement Mortar Mass Prepared with Recycled Demolished Concrete Aggregates

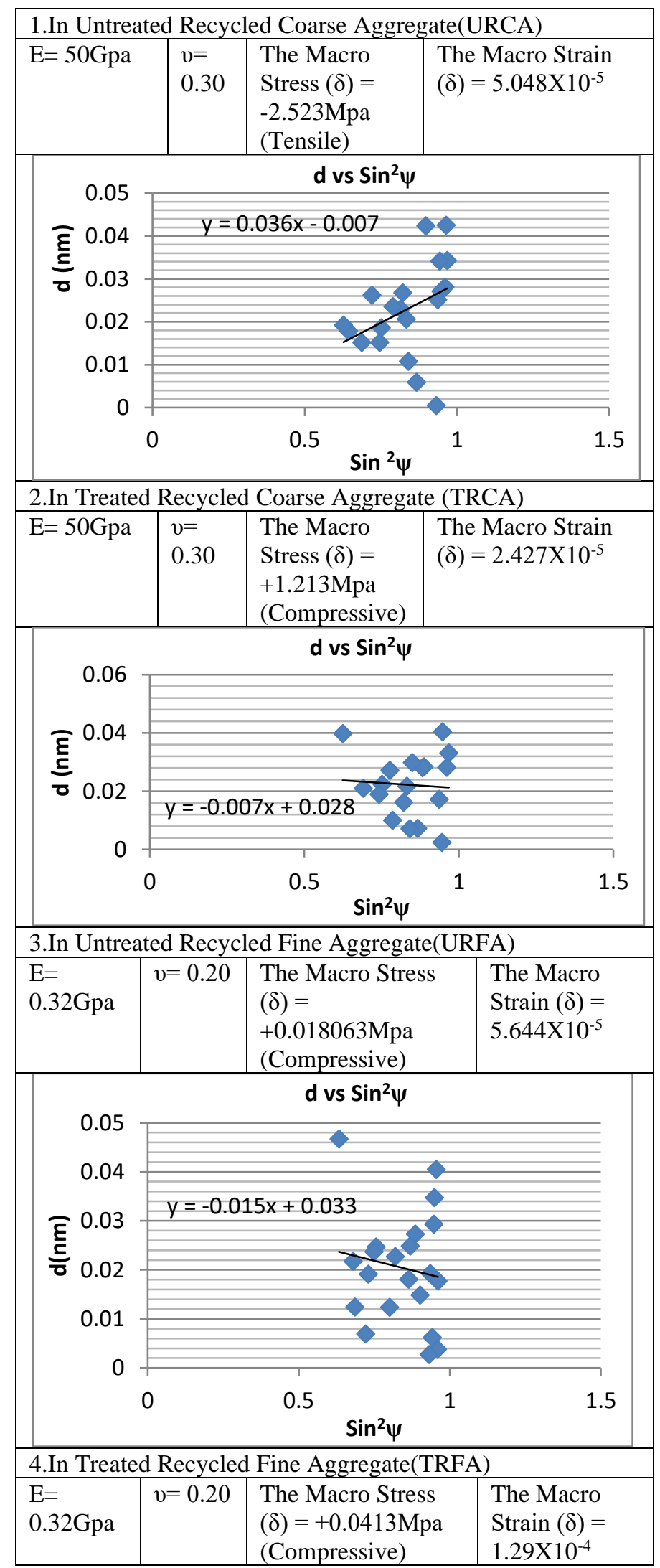


D. Durga Prasad and Kishore Ravande

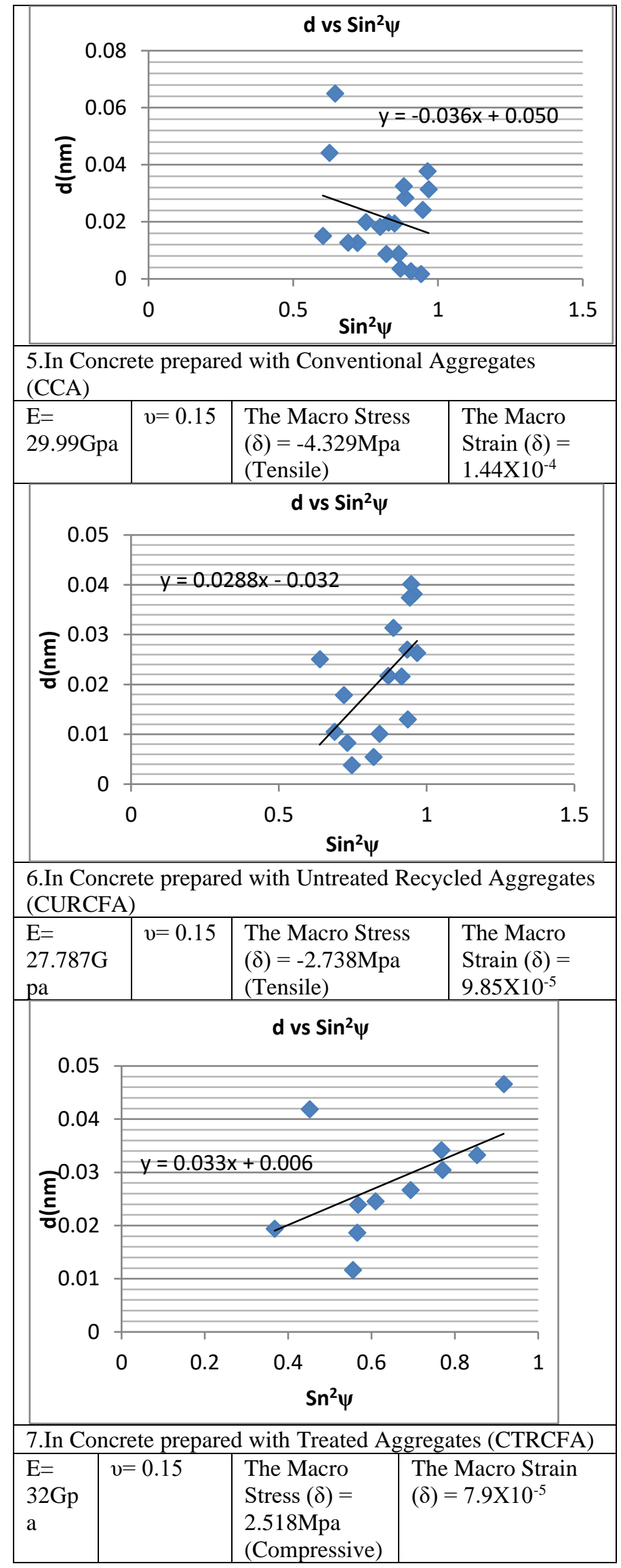


Evaluation of Internal Stresses and its Impact on the Concrete/Cement Mortar Mass Prepared with Recycled Demolished Concrete Aggregates

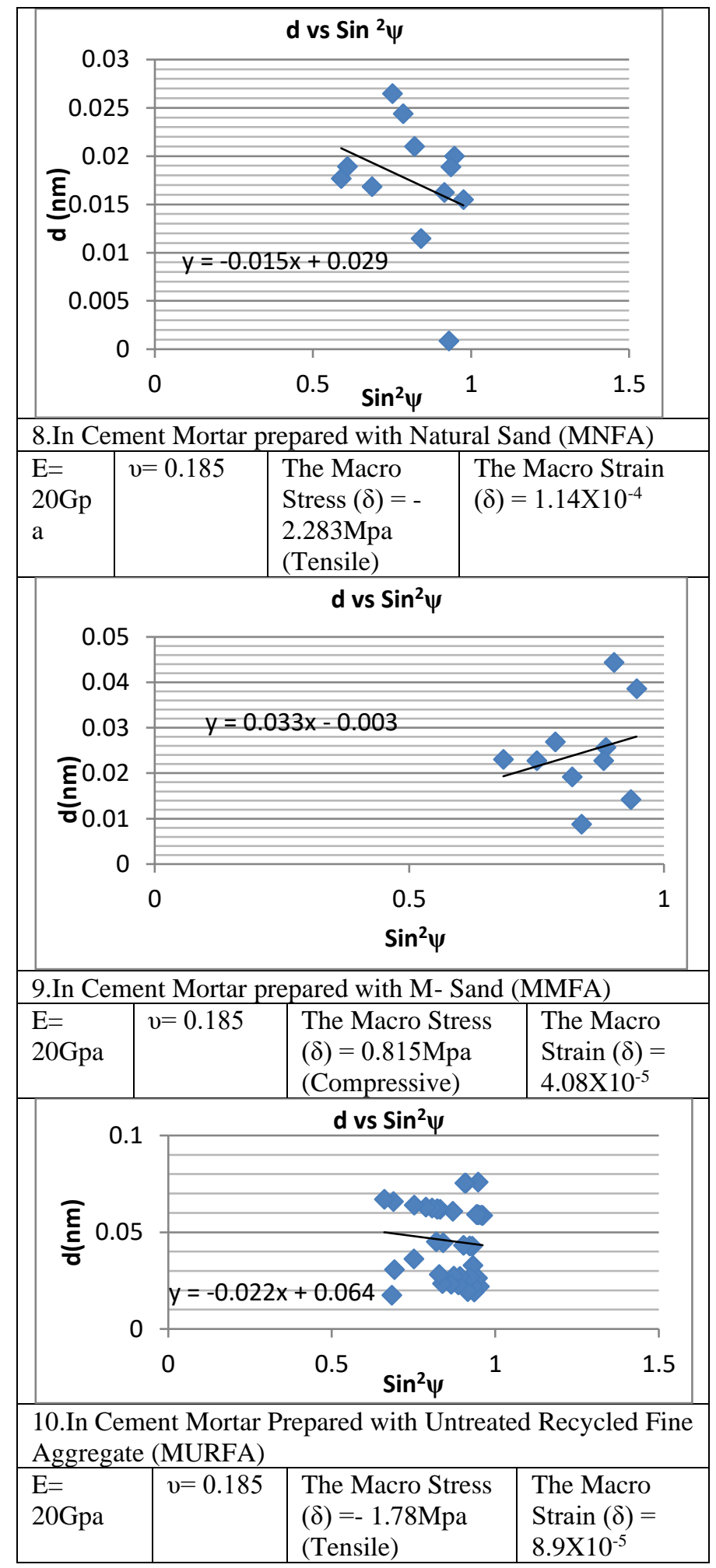




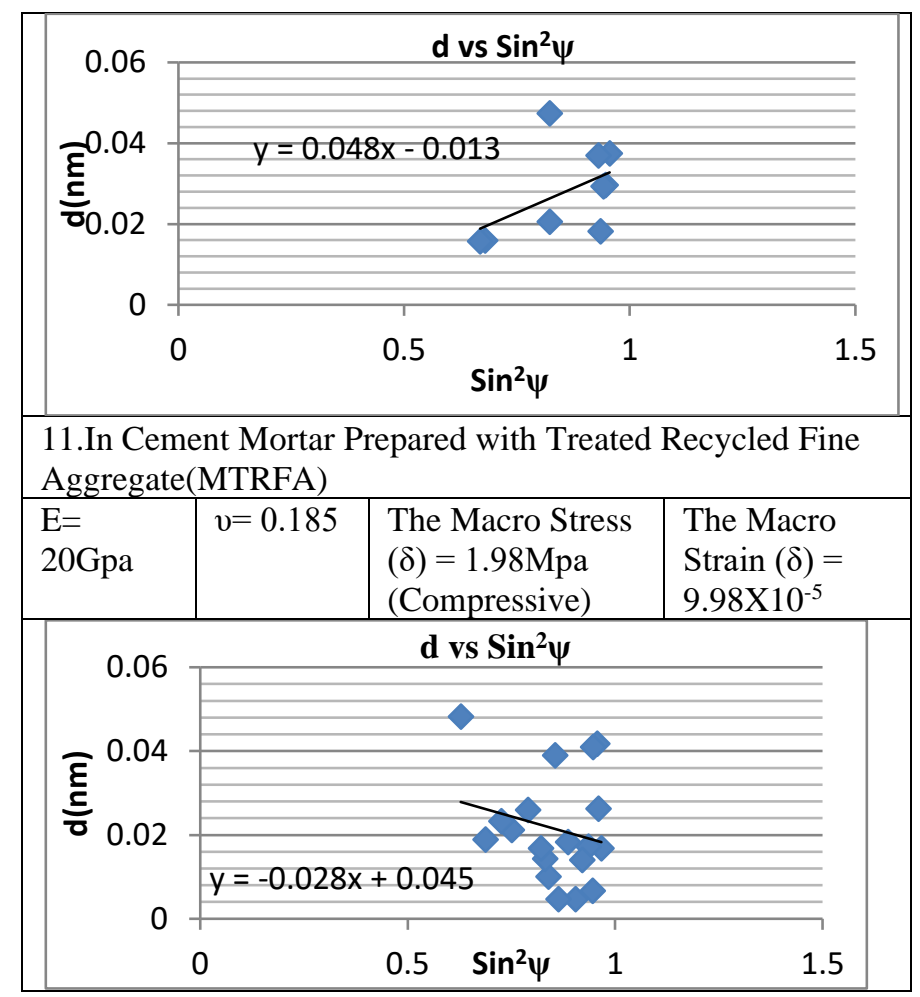

Figure 7 Macro Strain and Macro Stress calculation on Different Specimen

\subsubsection{Impact of Macro Stress}

The above tabulated values depicts the calculation of macro strain and macro stress values, from which it can be inferred that treatment on the surface of recycled demolished concrete aggregate has induced the compressive macro stresses on the aggregate surface and without treatment the stress are of tensile nature. The identification of compressive and tensile nature is done by position of plot between d vs $\operatorname{Sin}^{2} \psi$, as shown below in Figure 8. The usage of Treated Recycled aggregates in concrete and mortar mass developed macro stress of compressive nature on the surface of the mass, this was mainly due to adhered mortar mass on the recycled aggregate upon treatment is being converted into hard mass and this hard mass which intern being rich in silicates, upon its reaction with cementation material plays an active role and imparts further hardness and compressive nature to its surface. In untreated recycled demolished concrete aggregates the adhered mortar is loss and less reactive because of this nature, the macro stresses induced are of tensile nature. Similar is the case in concrete and mortar mass prepared with conventional aggregates, where the aggregates are playing a role of inert material and because of non reactive nature, it macro stresses induced are of tensile nature on the surface of the concrete and mortar mass. The development of macro stress for different samples under test is as depicted below,

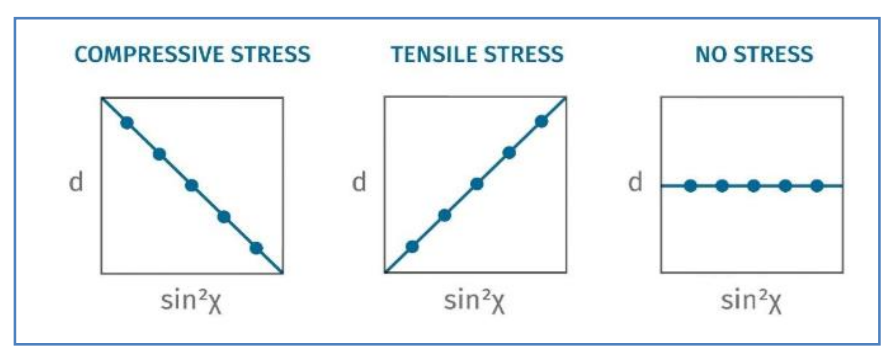

Figure 8 Macro Stresses is determined from the diffraction data by calculating the strain from the diffraction peak positions. 
Source Stresstech Bulletin 12

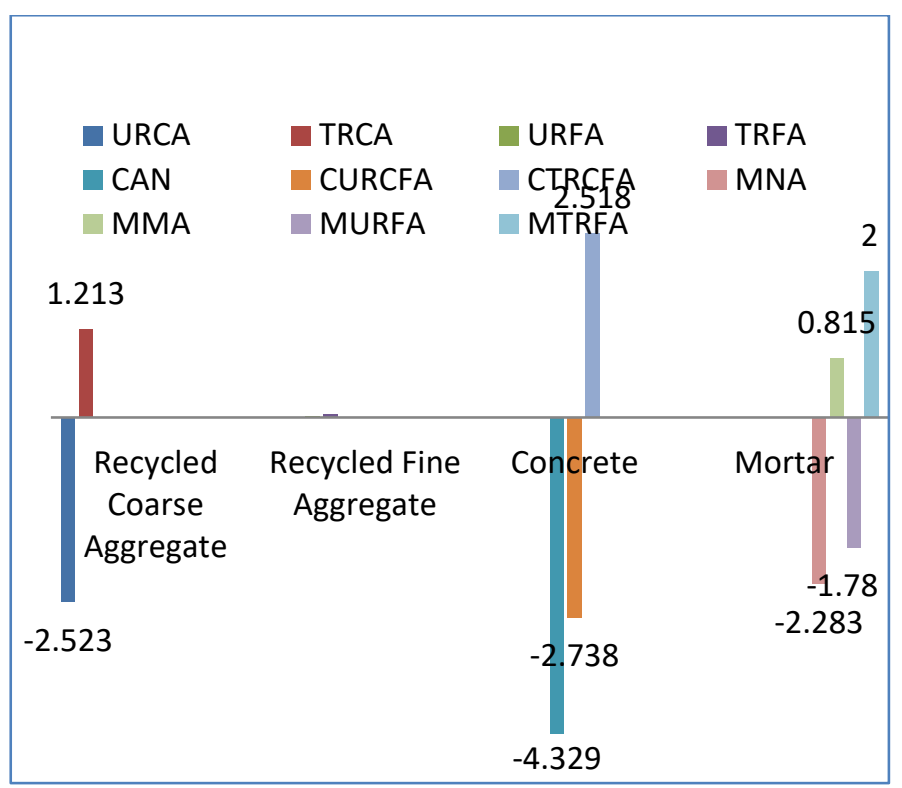

Figure 9 Macro Stress (Mpa) Values of Different Specimen Samples under test

\subsection{Micro strain and Micro stress Calculation}

The strain broadening due to crystallite micro distributions. It is defined by the crystallite non uniform variations of dhkl planes in a structure, which can be produced by the external stresses, crystalline defects (dislocation for instance) or local compositional variations (in solid solutions for instance) .It can be shown by the worked out equation i.e.,

$$
\beta=4 \varepsilon \operatorname{Tan} \theta---
$$

Where $\beta$ is the Full Width at Half Maximum is the diffraction angle, $\varepsilon$ is the microstrain relative non uniform deformation of the interplannar distance. The micro stress is calculated by multiplying the microstrain with the elastic constants. Both size and microstrain broadening effect produce a symmetric broadening. Microstrain in crystalline can come from a number sources; dislocation, vacancies, defects, shear planes, thermal expansion and contractions, etc., Whatever, the cause of the residual stress in a crystallite ,the effect will cause a distribution of $\mathrm{d}$-values about the normal, unstrained or micro strained $\mathrm{d}_{\mathrm{hkl}}$ value._Stress calculation is affected by material-based parameters such as differences in lattice parameters, precipitations, interstitial occupation, and micro stresses. In a poly-crystalline structure with disordered crystals at the grain boundaries, precipitations and lattice defects, the diffraction line widens and forms a Gaussian-like peak. The width of the peak is measured as Full Width at Half Maximum (FWHM) which illustrates micro stresses and/or hardness and plastic deformation; typically, value increases with increasing hardness. The below figure.10 depicts the types of strain development in crystal lattice, which corresponds to diffraction patters i.e. Uniform strain shifts the diffraction peak. Non-uniform strain can alter both the peak shape and position and no-strain peak will not alter the peak. 


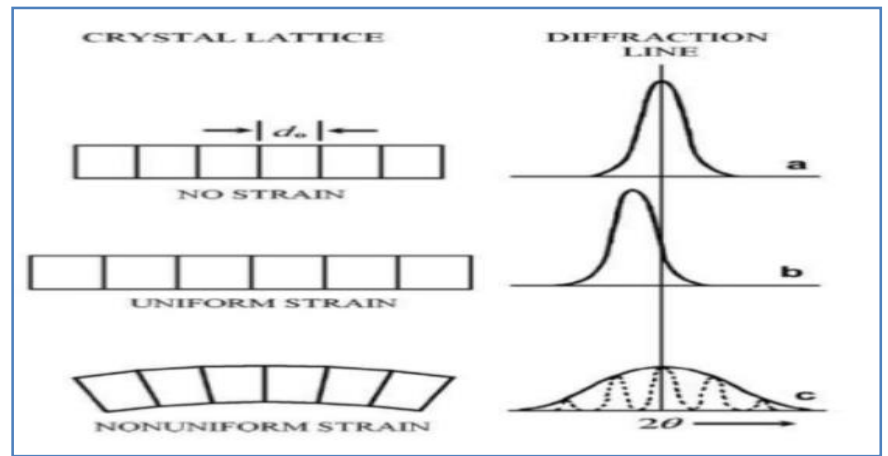

Figure 10 The Microstrain in Molecular Structure

Source: Khorsand Zak ef al/solid state science 13(2011) 251-256

\subsubsection{Impact of Micro Strain and Stress}

The Figure.11\&12 Depicts the Micro strain, a micro stress calculated from the X-ray diffraction data shows the same result as obtained for macro stress, the micro stress is of compressive nature in the recycled aggregates that are treated and also in the concrete \& cement mortar mass prepared with treated recycled aggregates. Whereas in untreated recycled aggregates and in the concrete \& Cement mortar mass prepared with untreated recycled aggregates and mass prepared with conventional aggregates has shown the tensile nature of micro stress development. While in mortar mass prepared with M-sand has only shown the compressive nature of micro stress formation. The reasons of compressive and tensile nature of microstress are same as defined for Macro stress

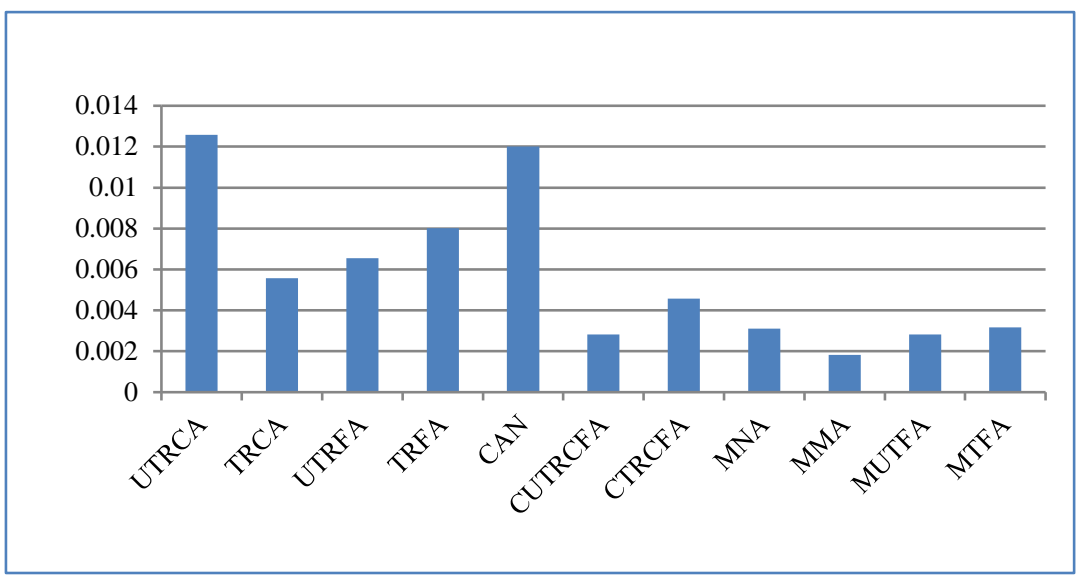

Figure 11 Micro Strain* $\left(x 10^{-2}\right)$ values of Different samples under study 


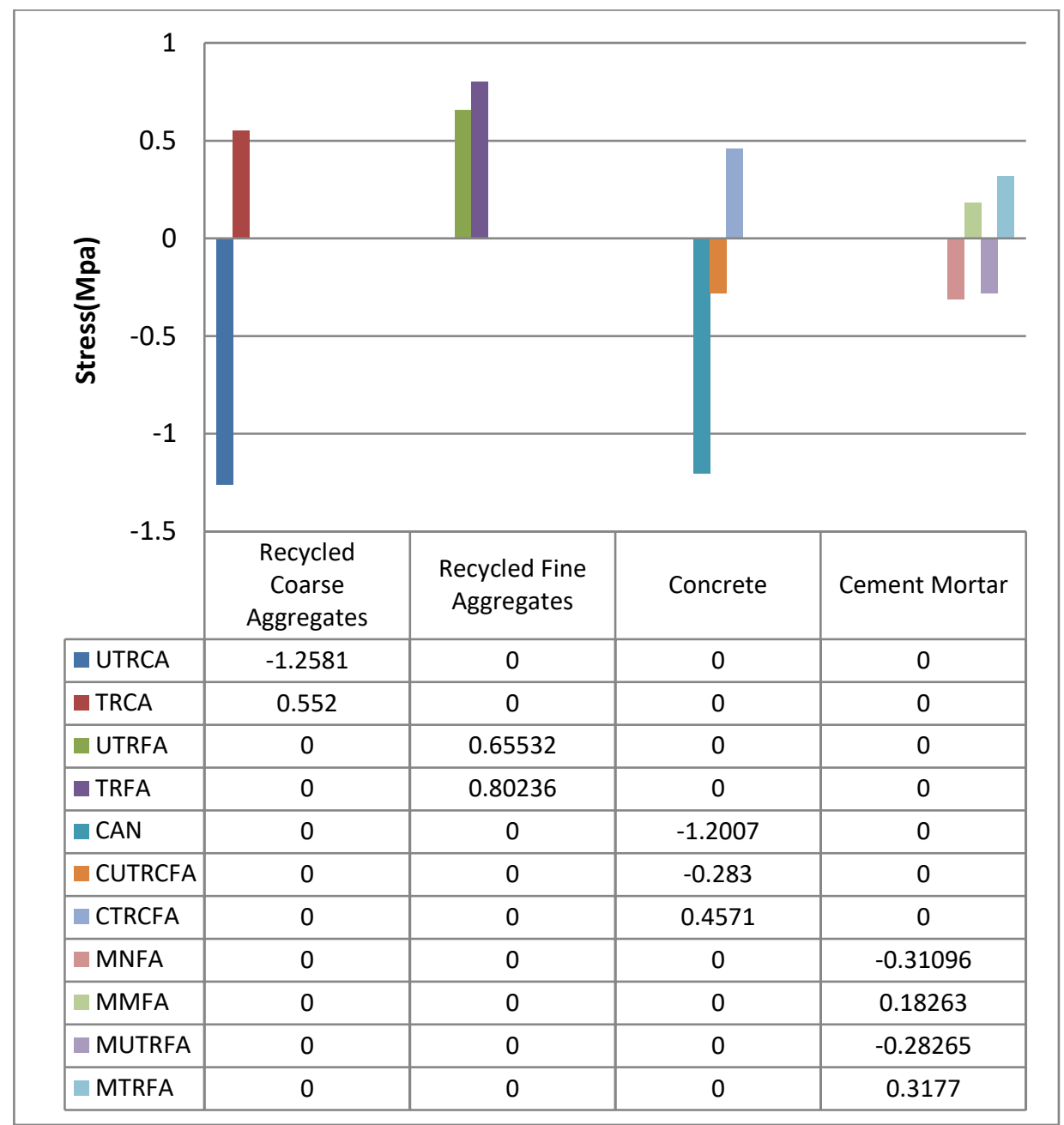

Figure 12 Micro Stress Values of Different Samples Under Test

\subsection{Impact of Net Induced Stress}

The residual stress determined using X-ray diffraction is the arithmetic sum of Marco Stress and Micro stress. Using the equation (A) and substituting the values of residual stress and the applied stress on the material i.e the applied stress on concrete and mortar mass is the 28-days compressive strength results as conducted on concrete cube and cement mortar cubes and as per the obtained results tabulated at Figure $1 \& 2$. The calculated net induced stresses are tabulated at Figure 14. From this calculations it can be inferred that the residual stress play a major role in identification of actual stress acting on the material/mass and also it throws the light on the design criteria stress to be considered for design of concrete structures .The calculation and also the graph plotted at Figure 14 shows that concrete mass prepared by treated recycled demolished concrete aggregates induces an average net stress of $43.415 \mathrm{Mpa}$ as against the net induced stress of $33.80 \mathrm{Mpa}$ present in concrete mass prepared with conventional Aggregates. Similarly in Cement mortar prepared with Treated recycled demolished concrete fine aggregates induces a net stress of 58.28Mpa as against 52.40 and $51.49 \mathrm{Mpa}$ on mortar sample prepared with conventional fine aggregates i.e. with river sand and with $\mathrm{M}$-sand. The Figure-13depicts the net stress induced on the treated and untreated aggregates samples under test. The treatment adopted on recycled demolished concrete aggregates found effective in inducing positive stress on the aggregates surface i.e. both on coarse and fine aggregates. 
D. Durga Prasad and Kishore Ravande

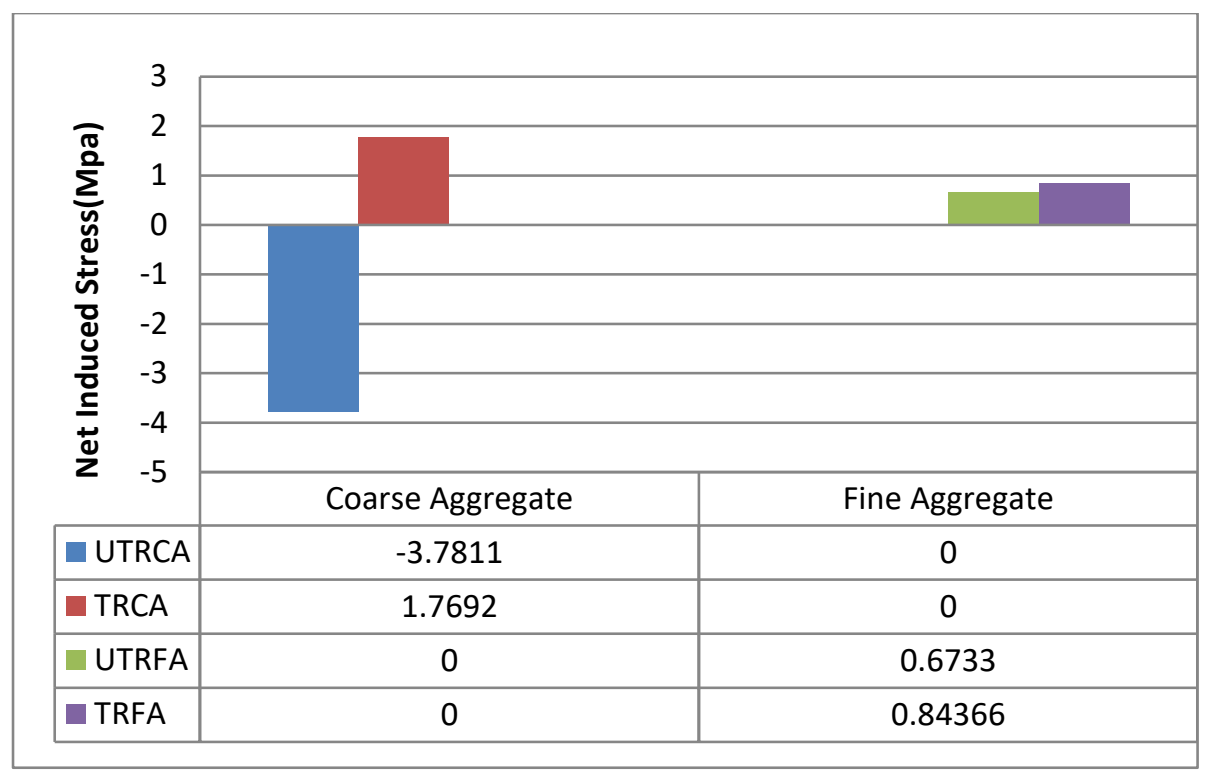

Figure 13 Net Induced Stress On Aggregate Samples

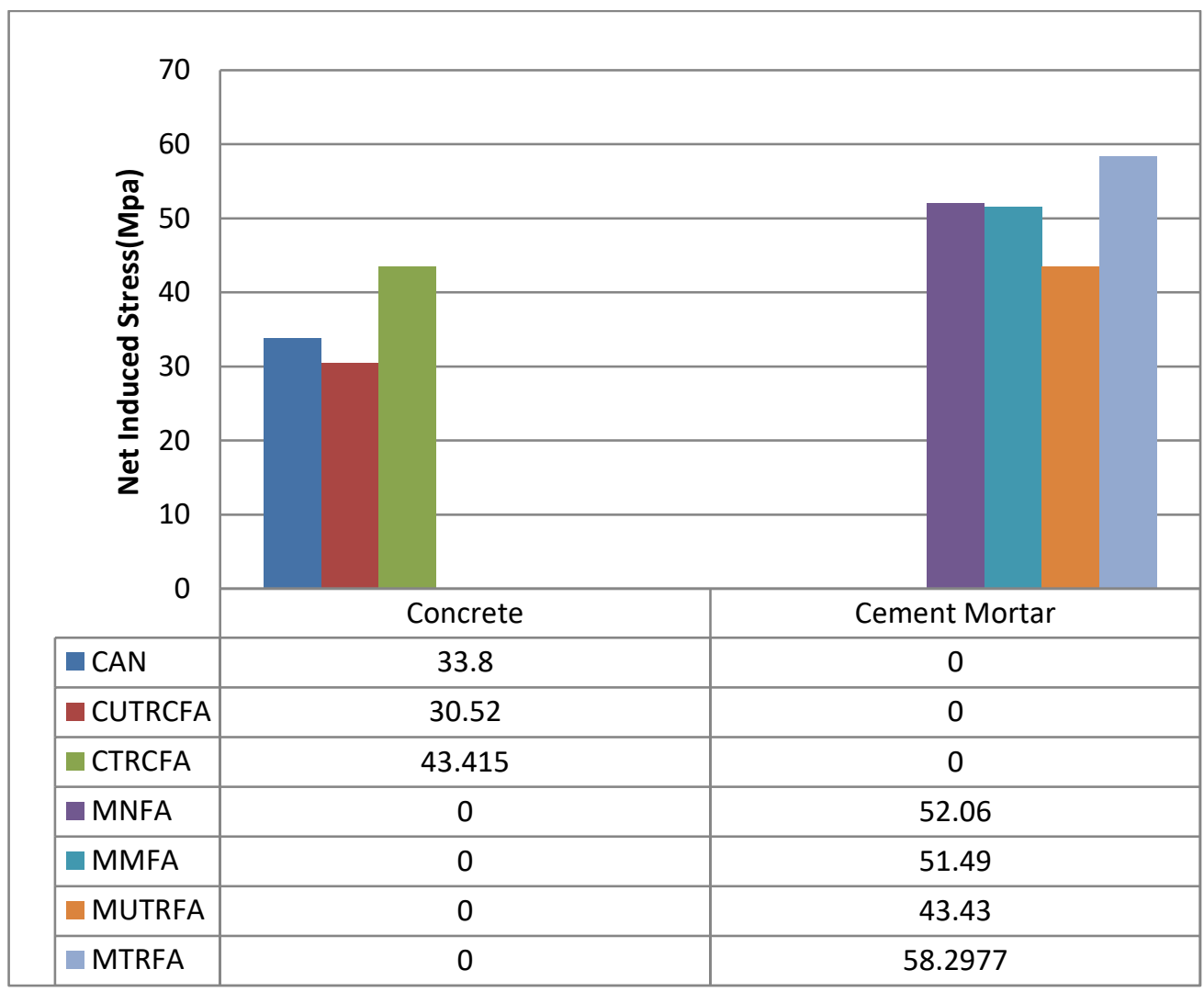

Figure 14 Net Induced Stress on Concrete and Cement Mortar Samples Prepared with Different Types of Aggregates

\section{CONCLUSIONS}

a. The XRD helps in evaluating the net induced stress on the sample under study and from the analysis, it can be concluded that residual stress plays a vital role in the design of concrete structures and also it effects the fatigue life of the structure, its resistance to corrosion, the effect of distortion and the dimension stability overall. 
b. The development of internal compressive nature macro and micro stress helps in bounding the internal grains and internal molecules as against the development of tensile stresses. Thus producing a mass with closely packed molecules.

c. The densification on recycled demolished concrete aggregates has induced compressive nature macro and micro stress on aggregates surface and its usage in concrete and mortar mass further developed the compressive nature residual stress. This indicates the active role played by the treated recycled demolished concrete aggregates.

d. The residual stress developed in concrete and mortar mass prepared with conventional aggregates and with untreated recycled demolished concrete aggregates are of tensile in nature. This indicates the inert role played by the conventional and untreated recycled aggregates.

e. The net induced stress from macro and micro in concrete and mortar mass prepared with densified recycled demolished concrete aggregates has resulted in its compressive loadcarrying capacity, formation of dense mass.

\section{REFERENCES}

[1] F A Kandil, J D Lord, A T Fry and P V Grant - A Review of Residual Stress Measurement Methods -A Guide to Technique Selection - NPL Materials Centre Queens Road Teddington, Middlesex, UK TW110LW - NPL Report MATC(A)20O4

[2] IS: 4031-1968, Indian Standard, Method of Physical Tests for Hydraulic Cement, Bureau of Indian Standards.

[3] IS: 2116-1980, Indian Standard, Specification for Sand for Masonry Mortars (first revision).

[4] IS: 2386-1963, Indian Standard, Methods of Test on Aggregates of Concrete (first revision).

[5] IS: 10262:2009, Indian Standard, Concrete Mix Proportioning-Guidelines (first revision).

[6] "Influence of anti-caking agent kaolin on film formation of ethylene-vinyl acetate and carboxylates styrene -butadiene latex polymers"- by Bauer egger, M, perello, J.Plank, Cement and Concrete Research 58(2014).

[7] "Durability of Reinforced Concrete Incorporating Recycled Concrete as Aggregate (RCA) "By Ramtin Movassaghi -A thesis presented to the University of Waterloo towards Fulfilment of Master of Applied Science.

[8] "Effect of Recycled Aggregates on the Mechanical Properties of Concrete- by Aastha, Dr.R.R.Singh- International Research Journal of Engineering and technology Volume: 05 Issue 10/Oct 2018

[9] "Improvement of recycled concrete aggregate properties by polymer treatments" -by Valerie Spaeth, Assia Djerbi Tegguer - International Journal of Sustainable Built Environment (2013)2

[10] "Influence of fine recycled concrete aggregates on the properties of mortars"- Zengfeng Zhao, Sebastien Remond, Denis Damidot, Weiya Xu-Construction and Building Materials 81(2015). 